\title{
In vitro antiproliferative and antimigratory activity of dasatinib in neuroblastoma and Ewing sarcoma cell lines
}

\author{
FABIO TIMEUS $^{1}$ NICOLETTA CRESCENZIO $^{1}$, ABDERRAHIM FANDI ${ }^{2}$, ALESSANDRA DORIA $^{1}$, \\ LUISELDA FOGLIA $^{1}$ and LUCA CORDERO DI MONTEZEMOLO ${ }^{1}$ \\ ${ }^{1}$ Department of Pediatric Hematology/Oncology, University of Turin, Italy; \\ ${ }^{2}$ Bristol-Myers Squibb, Lawrenceville, Princeton, USA
}

Received September 10, 2007; Accepted October 19, 2007

\begin{abstract}
Neuroblastoma (NB) and Ewing sarcoma (ES) are neuroectodermal tumors typical of pediatric age that, despite aggressive treatment, still present a poor prognosis when in advanced stages. Studies indicate that c-KIT and plateletderived growth factor receptor (PDGFR) play a substantial role in the proliferation and survival of NB and ES cells. Dasatinib, an oral multi-targeted inhibitor of several kinases including BCR-ABL and SRC-family kinases, is also active against c-KIT and PDGFR. Here, we evaluated the effect of dasatinib on the NB cell lines SJ-N-KP, SK-N-BE, AF8 and IMR5, and on the ES lines PDE02, TC106 and 6647. Proliferation and viability assays showed that dasatinib exerts an antiproliferative activity with a peak effect occurring at $24 \mathrm{~h}$. After a 24-h exposure to dasatinib at $100 \mathrm{nM}$, proliferation was inhibited by $29.4 \pm 5.7 \%$ in SJ-N-KP, $41.3 \pm 11.7 \%$ in IMR5, $35.3 \pm 7.6 \%$ in PDE02 and $14 \pm 10.6 \%$ in 6647. Dasatinib did not induce apoptosis in NB and ES cell lines. A possible antimigratory activity of dasatinib was evaluated by scratch test. Dasatinib at $100 \mathrm{nM}$ inhibited the migration of NB and ES cell lines by a mean of 30.2 and $25.3 \%$, respectively. This activity suggests a possible role of dasatinib in inhibiting metastasis and appears of particular interest, given the association between metastatic disease and poor prognosis in these tumors. In conclusion, the cytostatic and antimigratory activity of dasatinib in NB and ES cell lines and the lack of pro-apoptotic activity suggests a possible use for this compound in the treatment of these tumors as a combination with other cytotoxic therapy.
\end{abstract}

\section{Introduction}

Neuroblastoma (NB) and Ewing sarcoma (ES) are neuroectodermal tumors that most commonly affect pediatric

Correspondence to: Dr Fabio Timeus, Pediatric Hematology Unit, University of Torino, Piazza Polonia 94, 10126 Torino, Italy

E-mail: fabio.timeus@unito.it

Key words: dasatinib, neuroblastoma, Ewing sarcoma age (1). Despite advances in treatment, the prognosis of these patients remains poor. Twenty to $40 \%$ of patients with localized ES eventually die from the disease (2) and the overall survival rates for patients with NB were reported at $68.5 \%$ (3) In both neuroblastoma and Ewing sarcoma, metastatic disease is predictive of a particularly poor treatment outcome. The probability of long-term survival for patients with either metastatic neuroblastoma or Ewing sarcoma is $\sim 25 \%$, highlighting the need for new therapeutic approaches $(3,4)$.

Numerous studies have suggested that the tyrosine kinase platelet-derived growth factor receptor (PDGFR) and c-KIT are involved in the pathogenesis of Ewing sarcoma and neuroblastoma. In neuroblastoma cells, an autocrine stem cell factor (SCF)/c-KIT loop was shown to protect against apoptosis (5). Autocrine stimulation of KIT receptor has also been reported in Ewing sarcoma (6-8), implicated in tumor growth and metastasis (7) and suggested to prevent the initiation of apoptosis (8). Moreover, the simultaneous expression of c-KIT and SCF in neuroblastoma tumors was shown to be associated with a more aggressive phenotype $(9,10)$.

PDGFR is also expressed in Ewing sarcoma and neuroblastoma tumor cell lines $(11,12)$ and has been implicated in disease pathogenesis $(12,13)$. Zwerner and May showed that a platelet-derived growth factor (PDGF)$\mathrm{C} / \mathrm{PDGFR}$ autocrine loop may be involved in the neoplastic transformation of Ewing sarcoma cells (13). Furthermore, the inhibition of PDGFR signaling with a PDGFR-specific kinase inhibitor blocked growth and chemotaxis of TC-32 cells in vitro (12). Similarly, neuroblastoma cells were found to express PDGFR- $\alpha$ and $-\beta$ (11) and the inhibition of ligand stimulated-phosphorylation of both PDGFR and c-KIT correlated with the growth inhibition of neuroblastoma cells in vitro.

The involvement of PDGFR and c-KIT in Ewing sarcoma and neuroblastoma raises the possibility that these signaling molecules could be exploited as potential therapeutic targets.

Dasatinib (BMS-354825, SPRYCEL, Bristol-Myers Squibb, NY, USA), is an oral multi-targeted inhibitor of several kinases including BCR-ABL and SRC-family kinases (14). Additionally, dasatinib inhibits c-KIT and PDGFR, and has demonstrated activity against PDGFR and c-KITmediated cellular events (14). Chen et al showed that dasatinib 
inhibited PDGF-stimulated migration and proliferation of vascular smooth muscle cells at concentrations in the low nanomolar range (15). In another study, dasatinib was found to potently inhibit both wild-type and mutant forms of KIT (including imatinib-resistant forms) in mast and leukemic cell lines (16).

On the basis of this activity, coupled with the known role of PDGFR and c-KIT in the biology of neuroblastoma and Ewing sarcoma, we investigated the effects of dasatinib on the proliferation, viability and migration of neuroblastoma and Ewing sarcoma cell lines.

\section{Materials and methods}

Dasatinib preparation. All compounds were synthesized by the medicinal chemistry group at Bristol-Myers Squibb Pharmaceutical Research Institute. Compounds were solubilized in $100 \%$ DMSO at $10 \mathrm{mM}$ as stock solution for all experiments.

Cell cultures. Four neuroblastoma cell lines (SJ-N-KP, SK-NBE, AF8 and IMR5) and three Ewing sarcoma cell lines (PDE02, TC106 and 6647) were used in this study $(5,8,17)$. Cell lines were maintained in monolayer cultures in RPMI1640 medium $+10 \%$ fetal calf serum $($ FCS $)$.

Cell proliferation assays. To assess proliferation, cells were cultured in the presence or absence of dasatinib at 10, 50,100, $250,500,1,000,2,000,5,000$ and $10,000 \mathrm{nM}$ for 24,48 , or 72 h. Following exposure to dasatinib or DMSO (control), cells were harvested with trypsin and stained with trypan blue. Cellular proliferation was determined by quantifying viable cells manually using a hemocytometer. Viability was based on trypan blue exclusion. Inhibiting concentrations of $50 \%\left(\mathrm{IC}_{50}\right)$ were calculated by the SPSS 11.5 program. Experiments were performed in triplicate.

Apoptosis assays. Following 24- and 48-h exposure to dasatinib or DMSO (control), cells were harvested with trypsin. Apoptosis was evaluated by flow cytometry, using annexin V-FITC conjugates (Apoptosis Detection Kit, R\&D Systems), according to the manufacturer's instructions, with an EPICS XL2 flow cytometer. Experiments were performed in triplicate.

Cell cycle analysis. Cell cycle was evaluated using the Coulter Prep Reagents kit (Beckman Coulter, CA, USA). Cells were processed according to the protocol following a 24- or 48-h exposure to dasatinib or DMSO (control) and analyzed by flow cytometry. Experiments were performed in triplicate.

Cell migration assays. Cell migration was evaluated using the scratch test as previously described (18). In brief, cells were grown to confluence on tissue culture dishes and a single scrape was made in the confluent monolayer using a sterile pipette tip. After washing the cells in PBS, a complete medium containing dasatinib (100 $\mathrm{nM}$ ) or DMSO (control) was added. Cells were then incubated for an additional $48 \mathrm{~h}$. The number of cells that migrated beyond the borders of the scrape were then quantified (18).

\section{Results}

Proliferation assays performed on neuroblastoma (SJ-N-KP and IMR5) and Ewing sarcoma (PDE02 and 6647) cell lines following a 24-, 48- or 72-h exposure to dasatinib, demonstrated a concentration-dependent antiproliferative effect of dasatinib in both NB and ES cell lines with a peak effect occurring at $24 \mathrm{~h}$ (Fig. 1). $\mathrm{IC}_{50}$ values calculated from the cell proliferation assays showed that the comparative sensitivity to dasatinib was $6647<$ SJ-N-KP $<$ IMR5 < PDE02. $\mathrm{IC}_{50}$ at 24 and $48 \mathrm{~h}$ were respectively 6,112 and $4,970 \mathrm{nM}$ for SJ-N-KP, 1,379 and 31,513 nM for IMR5, 433 and $661 \mathrm{nM}$ for PDE02, 19,897 and 21,142 nM for 6647 cell lines.

To evaluate a possible pro-apoptotic effect of dasatinib on neuroblastoma and Ewing sarcoma lines annexin-V/PI staining was quantified in SJ-N-KP and PDE02 cells treated with various concentrations of dasatinib $(50,100,250,500,1,000$ and 2,000 nM). The 6647 and IMR5 lines were evaluated for apoptosis only after exposure to dasatinib at $100 \mathrm{nM}$. Dasatinib did not induce apoptosis in neuroblastoma and Ewing sarcoma cells (Table I).

Cell cycle effects of dasatinib were analyzed in neuroblastoma cells (SJ-N-KP and IMR5) and in Ewing sarcoma cells (6647 and PDE02) after 24-, 48-, 72-h exposure to dasatinib at $100 \mathrm{nM}$. Exposure to dasatinib for $48 \mathrm{~h}$ induced a mean S-phase reduction of $28.1 \%$ and a $34.8 \%$ increase in G0/G1 in 6647 and IMR 5 cells (Table II, Fig. 2). No significant effect on cell cycle was observed in SJ-N-KP and PDE02 cells (data not shown).

The scratch test demonstrated an inhibitory effect of dasatinib on cell migration in all of the NB and ES lines, ranging from a mean of 12 to $42 \%$ (Table III, Figs. 3 and 4).

\section{Discussion}

The expression of c-KIT and PDGFR in Ewing sarcoma and neuroblastoma tumor cells suggested that inhibiting these signaling molecules may be an effective treatment strategy. Evidence of a c-KIT/SCF autocrine loop was previously demonstrated in each of the cell lines used in this study $(5,8)$.

The known activity of dasatinib against c-KIT and PDGFR provided the basis for testing effects of this agent. Our results show that dasatinib induces substantial anti-proliferative and antimigratory effects on both Ewing sarcoma and neuroblastoma cells in vitro.

A dose-dependent antiproliferative effect was observed in all of the cell lines tested and occurred rapidly with the peak effect at $24 \mathrm{~h}$. It should be noted that the $\mathrm{IC}_{50}$ values calculated for the Ewing sarcoma and neuroblastoma cell lines used in this study were substantially higher than those reported for other cell types (14). However, after a 24-h exposure to the relatively low concentration of $100 \mathrm{nM}$, proliferation was inhibited by $29.4 \pm 5.7 \%$ in SJ-N-KP, $41.3 \pm 11.7 \%$ in IMR5, $35.3 \pm 7.6 \%$ in PDE02 and $14 \pm 10.6 \%$ in 6647 cell lines. Dasatinib at $100 \mathrm{nM}$ also induced a reduction of the $\mathrm{S}$ phase and an increase in the G0/G1 phase of the cell cycle in 6647 (Ewing sarcoma) and IMR5 (neuroblastoma) lines.

The effects of dasatinib on Ewing sarcoma and neuroblastoma cells appears to be cytostatic, whereas results 

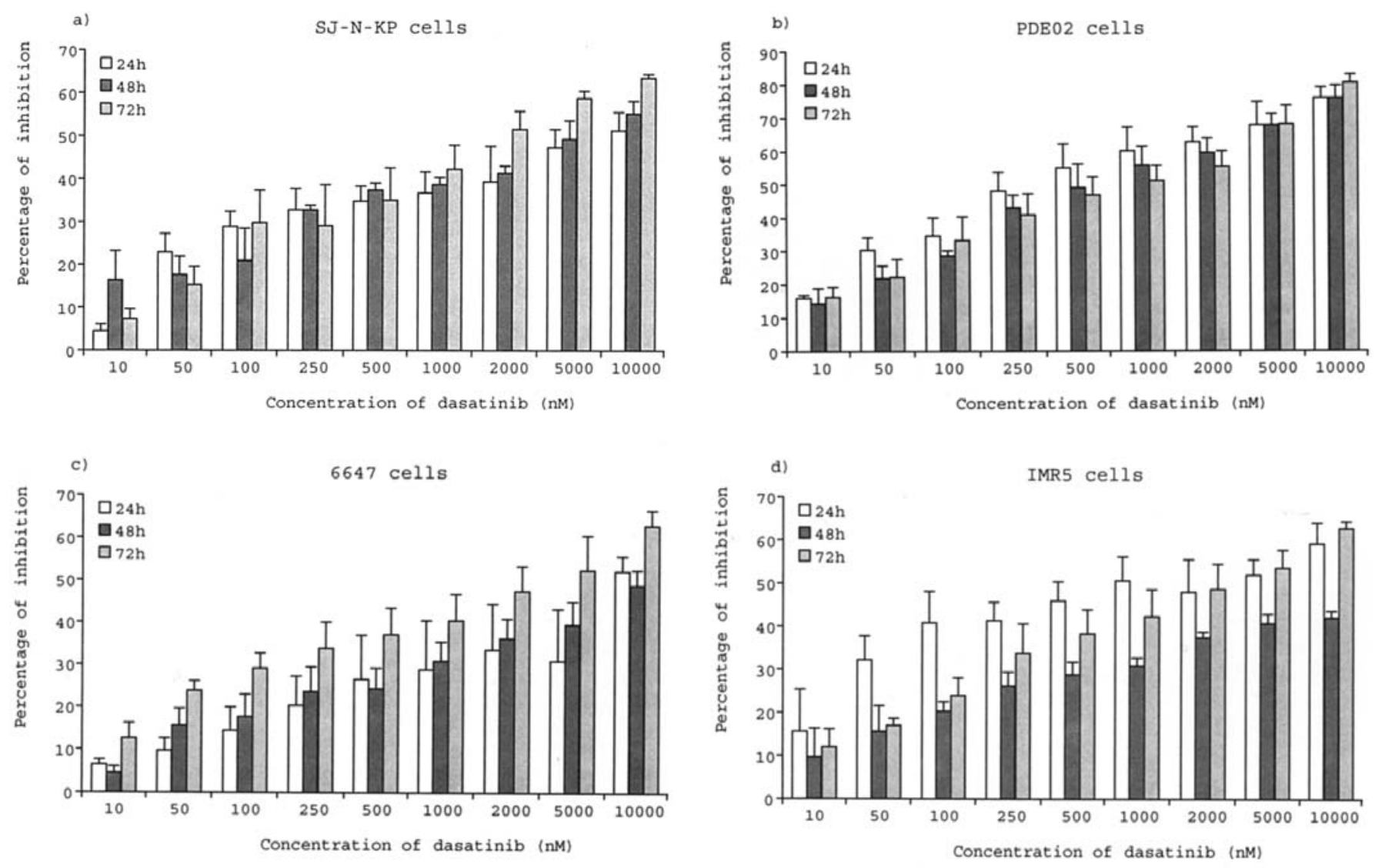

Figure 1. Dasatinib inhibits proliferation of neuroblastoma (SJ-N-KP and SK-N-BE) and Ewing sarcoma (PDE02 and 6647) cells. Percentage of proliferation inhibition at various concentrations of dasatinib after 24,48 or $72 \mathrm{~h}$. The values represent the mean of triplicate samples.
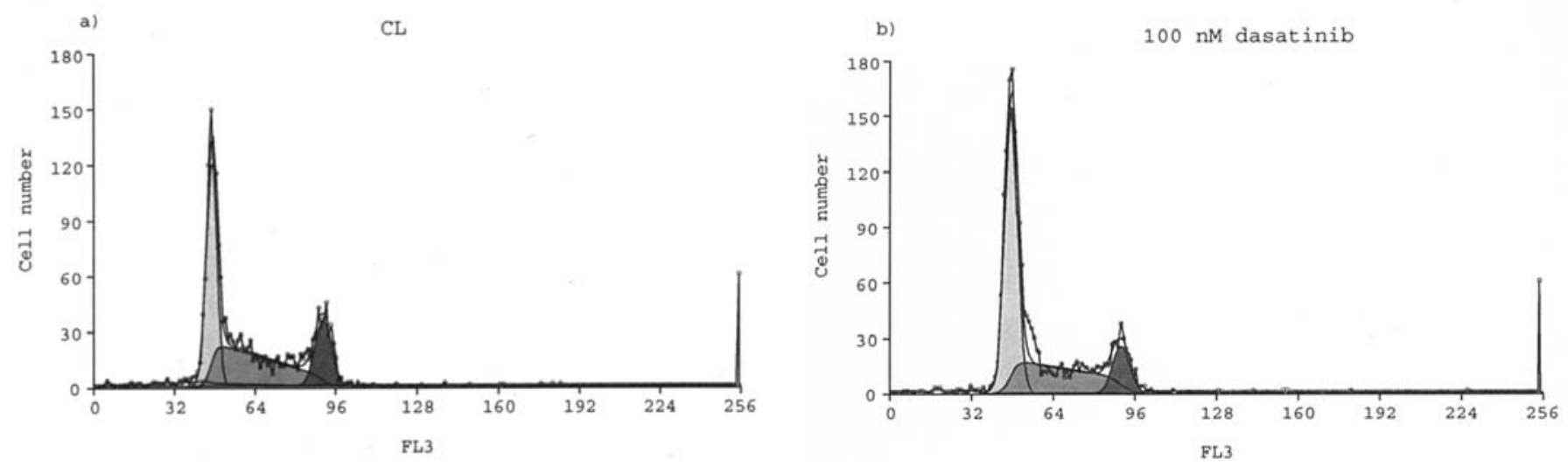

Figure 2. A representative flow cytometric evaluation of cell cycle in the IMR5 cell line. An increase in G0/G1 phase and a decrease in the S phase after a $48 \mathrm{~h}$ exposure to dasatinib at $100 \mathrm{nM}$. CL, control.

from apoptosis assays showed that dasatinib did not induce cell death in any of the cell lines tested.

Dasatinib treatment inhibited the migration of neuroblastoma and Ewing sarcoma cell lines by a mean of 30.2 and $25.3 \%$, respectively. This effect occurred at $100 \mathrm{nM}$, a concentration well below the calculated $\mathrm{IC}_{50}$ for proliferation. The dasatinib-mediated inhibition of cell migration likely occurs through its effects on c-KIT and PDGFR. SCF plays a central role in the migration of neural crest-derived cells (19). SCF has been shown to induce migration of Ewing sarcoma cells (7). Scotlandi et al reported that imatinib blocked SCF- mediated migration of Ewing sarcoma cells expressing high levels of c-KIT (20). Similarly, Uren et al showed that the Ewing sarcoma cell line TC-32 migrated towards PDGF-BB and that this migration was inhibited when PDGFR- $B$ activation was blocked with AG1295 (12). Other reports have demonstrated that the antimetastatic effects of dasatinib in a variety of tumor models were linked to its potent activity against SRC (18,21-23). Furthermore, SRC has been implicated in PDGF-dependent chemotaxis (24). The involvement of SRC in PDGF-mediated and other forms of cellular migration suggests the possibility that, in addition to 
Table I. Dasatinib does not induce apoptosis in the SJ-N-KP or PDE02 cell lines.

A, Neuroblastoma (SJ-N-KP)

\begin{tabular}{|c|c|c|c|c|}
\hline \multirow[t]{2}{*}{ SJ-N-KP } & \multicolumn{4}{|l|}{ Apoptosis (\%) } \\
\hline & Annexin $\mathrm{V}^{+}$ & $\mathrm{PI}^{+} /$Annexin $\mathrm{V}^{+}$ & $\mathrm{PI}^{+}$ & Alive \\
\hline CL (24 h) & 2.03 & 3.68 & 2.03 & 92.25 \\
\hline $50 \mathrm{nM}$ & 1.45 & 2.55 & 1.65 & 94.40 \\
\hline $100 \mathrm{nM}$ & 0.78 & 2.30 & 1.53 & 95.45 \\
\hline $250 \mathrm{nM}$ & 1.25 & 2.93 & 1.18 & 94.65 \\
\hline $500 \mathrm{nM}$ & 1.75 & 3.05 & 0.95 & 94.25 \\
\hline $1,000 \mathrm{nM}$ & 2.18 & 3.25 & 0.80 & 93.75 \\
\hline $2,000 \mathrm{nM}$ & 2.10 & 3.05 & 1.00 & 93.80 \\
\hline CL (48 h) & 2.10 & 3.05 & 3.45 & 91.4 \\
\hline $50 \mathrm{nM}$ & 1.75 & 2.15 & 5.75 & 90.4 \\
\hline $100 \mathrm{nM}$ & 4.25 & 3.30 & 6.55 & 85.9 \\
\hline $250 \mathrm{nM}$ & 0.20 & 3.45 & 7.20 & 89.1 \\
\hline $500 \mathrm{nM}$ & 2.35 & 3.95 & 5.05 & 88.6 \\
\hline $1,000 \mathrm{nM}$ & 2.85 & 3.20 & 5.50 & 88.4 \\
\hline $2,000 \mathrm{nM}$ & 0.35 & 0.95 & 5.25 & 93.4 \\
\hline
\end{tabular}

B, Ewing sarcoma (PDE02)

\begin{tabular}{lcccc}
\hline PDE02 & $(\%)$ & & & \\
& Annexin $\mathrm{V}^{+}$ & & PI $^{+}$ & Alive $^{+}$/Annexin $\mathrm{V}^{+}$ \\
\hline CL $(24 \mathrm{~h})$ & 5.20 & 2.15 & 1.95 & 90.75 \\
$50 \mathrm{nM}$ & 3.63 & 2.18 & 1.45 & 92.70 \\
$100 \mathrm{nM}$ & 2.48 & 1.70 & 1.68 & 94.10 \\
$250 \mathrm{nM}$ & 3.35 & 1.35 & 1.50 & 93.75 \\
$500 \mathrm{nM}$ & 3.98 & 2.78 & 2.13 & 91.20 \\
$1,000 \mathrm{nM}$ & 3.55 & 1.85 & 1.38 & 93.30 \\
$2,000 \mathrm{nM}$ & 1.93 & 1.13 & 3.30 & 93.65 \\
CL $(48 \mathrm{~h})$ & 0.95 & 3.45 & 5.10 & 90.5 \\
$50 \mathrm{nM}$ & 0.75 & 1.65 & 2.20 & 95.4 \\
$100 \mathrm{nM}$ & 0.35 & 0.85 & 4.60 & 94.2 \\
$250 \mathrm{nM}$ & 0.25 & 0.45 & 3.00 & 96.3 \\
$500 \mathrm{nM}$ & 0.65 & 0.90 & 2.10 & 96.4 \\
$1,000 \mathrm{nM}$ & 1.80 & 2.95 & 2.20 & 93.0 \\
$2,000 \mathrm{nM}$ & 0.90 & 3.90 & 2.80 & 92.4 \\
\hline
\end{tabular}

its direct effects on c-KIT and PDGFR, the anti-SRC activity of dasatinib may play a role in inhibiting neuroblastoma and Ewing sarcoma cell migration.

The inhibitory effect of dasatinib on neuroblastoma and Ewing sarcoma cell migration is of particular interest. While further studies are necessary to fully characterize the antimetastatic activity of dasatinib, the results presented here suggest that dasatinib may prevent metastasis of certain neuroblastoma and Ewing sarcoma tumors in vivo. Given the association between metastatic disease and poor prognosis in these tumors $(3,4,25)$, the inhibition of metastasis could have a significant impact on the overall treatment outcome of patients with these diseases.

Another c-KIT/ PDGFR inhibitor, imatinib, has also shown activity against neuroblastoma and Ewing sarcoma cells. In preclinical studies, imatinib inhibited the growth of both Ewing sarcoma and neuroblastoma cells $(6,9,20,26-28)$. Several of these reports have linked the activity of imatinib in 
Table II. Cell cycle modifications in IMR5 and 6647 cell lines after exposure to dasatinib at $100 \mathrm{nM}$ for 24, 48 and $72 \mathrm{~h}$.

\begin{tabular}{lcccr}
\hline & G0/G1 CL & G0/G1 dasatinib & S CL & S dasatinib \\
\hline IMR5 24 h & $49 \pm 3.2 \%$ & $39.7 \pm 3.7$ & $30.8 \pm 3.8$ & $39 \pm 3.3$ \\
IMR5 48 h & $41.1 \pm 4.6$ & $52.4 \pm 5.5$ & $39.2 \pm 2.2$ & $29.6 \pm 2.1$ \\
IMR5 72 h & $53.2 \pm 2.5$ & $68.2 \pm 1.6$ & $28.9 \pm 2.7$ & $20.9 \pm 1.5$ \\
6647 24 h & $42.1 \pm 17$ & $38.5 \pm 3.6$ & $38.7 \pm 11.9$ & $44.8 \pm 3.4$ \\
6647 48 h & $41.8 \pm 0.7$ & $59.4 \pm 3.8$ & $40.9 \pm 1.5$ & $27.9 \pm 4.0$ \\
$664772 \mathrm{~h}$ & $57.0 \pm 4.9$ & $73.2 \pm 1.6$ & $26.2 \pm 2.5$ & $17.9 \pm 1.9$ \\
\hline
\end{tabular}

CL, control.

Table III. Percentage of inhibition of migration in neuroblastoma and Ewing sarcoma cell lines evaluated by scratch test after exposure to dasatinib at $100 \mathrm{nM}$ for $48 \mathrm{~h}$.

\begin{tabular}{ll}
\hline & $48 \mathrm{~h}$ \\
\hline NB & \\
SJ-N-KP & $33 \pm 9.6 \%$ \\
IMR5 & $20 \pm 2.1 \%$ \\
SK-N-BE & $30 \pm 1.4 \%$ \\
AF8 & $38 \pm 11.3 \%$ \\
ES & \\
PDE02 & \\
TC106 & $42 \pm 7.8 \%$ \\
6647 & $22 \pm 8.5 \%$ \\
\hline
\end{tabular}

Ewing sarcoma cells to c-KIT inhibition $(6,20,26,27)$. However, other studies showed that imatinib inhibited the growth of cells not expressing c-KIT (9) and that SCF stimulation persisted during imatinib treatment (28), suggesting that the activity of this agent is at least partially independent of its effects on c-KIT. Beppu et al showed that the activity of

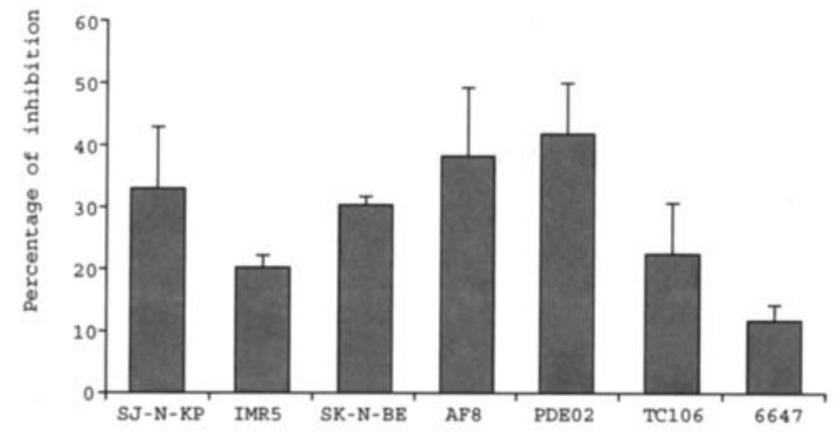

Figure 3. A scratch test in neuroblastoma and Ewing sarcoma lines after exposure to dasatinib at $100 \mathrm{nM}$ for $48 \mathrm{~h}$. Bars show the percentage of inhibition of cell migration through the scrape.

imatinib in neuroblastoma cells coincided with its inhibition of ligand-stimulated activity of both c-KIT and PDGFR (26). Furthermore, treatment with another PDGFR-specific inhibitor (AG1295) delayed the formation of Ewing sarcoma family tumors in animal models (12). These latter reports suggest that both c-KIT and PDGF are potential targets for the treatment of neuroectodermal-derived tumor cells.

While imatinib has shown preclinical efficacy against both Ewing sarcoma and neuroblastoma cells growing in vitro and
A

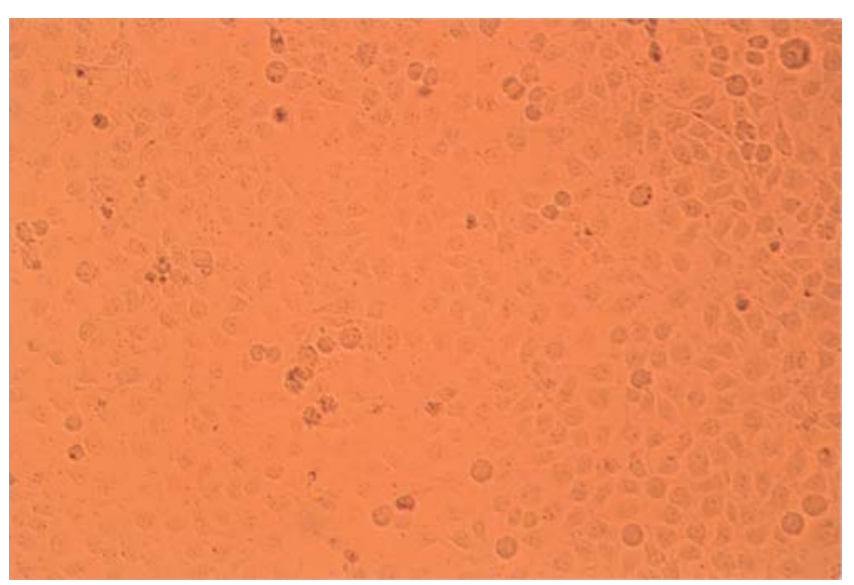

B

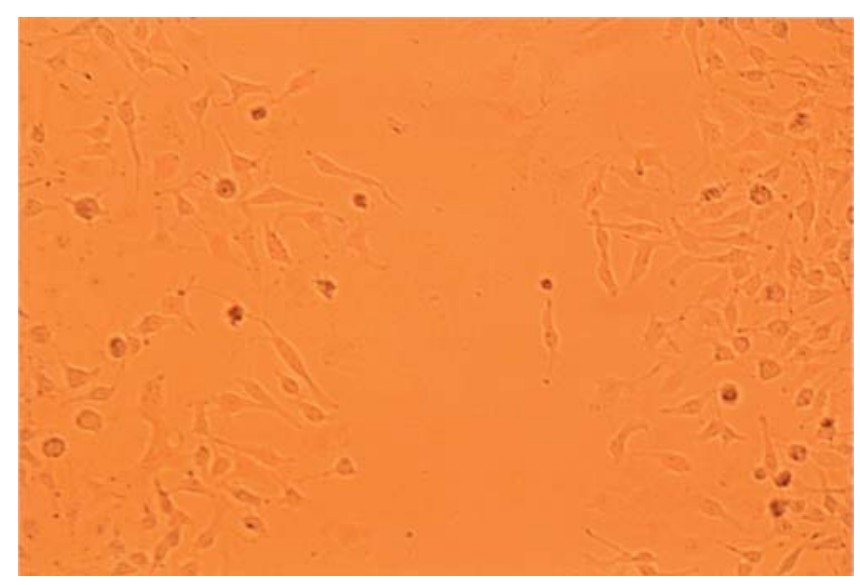

Figure 4. A Scratch test in the SJ-N-KP line. (A) In the control, the scrape is entirely filled by migrating cells. (B) Substantial inhibition of cell migration through the scrape. 
in vivo $(6,9,20,26-28)$, clinical results in this indication have been disappointing. In a phase II study in pediatric patients with relapsed or refractory solid tumors, single agent imatinib had only minimal efficacy, with a partial response in only $1 / 24$ patients with Ewing sarcoma and no responses among 10 patients with neuroblastoma (29).

The greater activity of dasatinib against PDGFR and c-KIT compared with that of imatinib may allow for improved efficacy in neuroblastoma and Ewing sarcoma tumors expressing these targets (14-16). Moreover, the potent effects of dasatinib on SRC may improve the treatment response of dasatinib in Ewing sarcoma cells.

Recently reported results from an ongoing clinical trial showed that dasatinib had a favorable safety profile in pediatric patients with relapsed or refractory leukaemia (30), suggesting that this agent could be used safely for treating young children and adolescents with neuroblastoma or Ewing sarcoma.

In conclusion, the antiproliferative and antimigratory activity of dasatinib on neuroblastoma and Ewing sarcoma cell lines may be clinically beneficial in the treatment of these tumors. However, the lack of apoptotic response suggests that dasatinib will likely yield the greatest clinical effect when combined with another cytotoxic therapy. Animal studies are warranted.

\section{Acknowledgements}

The authors would like to thank Johnathan Maher and Andrew Richardson for providing medical writing assistance (supported by research funding from Bristol-Myers Squibb). This study was partially supported by a Banca del Piemonte and Unione Genitori Italiani (UGI) grant.

\section{References}

1. Parham DM: Neuroectodermal and neuroendocrine tumors principally seen in children. Am J Clin Pathol 115: S113-S128, 2001 .

2. Thacker MM, Temple HT and Scully SP: Current treatment for Ewing's sarcoma. Expert Rev Anticancer Ther 5: 319-331, 2005.

3. Maris J and Shusterman S: Neuroblastoma. In: Cancer medicine. Kufe D (ed). $7^{\text {th }}$ edition, American Association for Cancer Research, pp1990-2005, 2006.

4. Gorlick R, Bernstein M, Toretsky J, Lor Randall R, Gebhardt M, Teot L, Wolden S and Marina N: Pediatric bone tumors. In: Cancer medicine. Kufe D (ed). $7^{\text {th }}$ edition, American Association for Cancer Research, pp2019-2027, 2006.

5. Timeus F, Crescenzio N, Valle P, Pistamiglio P, Piglione M, Garelli E, Ricotti E, Rocchi P, Strippoli P, Cordero di Montezemolo L, Madon E, Ramenghi U and Basso G: Stem cell factor suppresses apoptosis in neuroblastoma cell lines. Exp Hematol 25: 1253-1260, 1997.

6. Gonzalez I, Andreu EJ, Panizo A, Inoges S, Fontalba A, Fernandez-Luna JL, Gaboli M, Sierrasesumaga L, Martin-Algarra S, Pardo J, Prosper F and de Alava E: Imatinib inhibits proliferation of Ewing tumor cells mediated by the stem cell factor/KIT receptor pathway, and sensitizes cells to vincristine and doxorubicin-induced apoptosis. Clin Cancer Res 10: 751-761, 2004.

7. Landuzzi L, De Giovanni C, Nicoletti G, Rossi I, Ricci C, Astolfi A, Scopece L, Scotlandi K, Serra M, Bagnara GP, Nanni P and Lollini PL: The metastatic ability of Ewing's sarcoma cells is modulated by stem cell factor and by its receptor c-kit. Am J Pathol 157: 2123-2131, 2000.

8. Ricotti E, Fagioli F, Garelli E, Linari C, Crescenzio N, Horenstein AL, Pistamiglio P, Vai S, Berger M, di Montezemolo LC, Madon E and Basso G: C-kit is expressed in soft tissue sarcoma of neuroectodermic origin and its ligand prevents apoptosis of neoplastic cells. Blood 91: 2397-2405, 1998.
9. Vitali R, Cesi V, Nicotra MR, McDowell HP, Donfrancesco A, Mannarino O, Natali PG, Raschella G and Dominici C: C-Kit is preferentially expressed in MYCN-amplified neuroblastoma and its effect on cell proliferation is inhibited in vitro by STI-571. Int J Cancer 106: 147-152, 2003.

10. Uccini S, Mannarino O, McDowell HP, Pauser U, Vitali R, Natali PG, Altavista P, Andreano T, Coco S, Boldrini R, Bosco S, Clerico A, Cozzi D, Donfrancesco A, Inserra A, Kokai G, Losty PD, Nicotra MR, Raschella G, Tonini GP and Dominici C: Clinical and molecular evidence for c-kit receptor as a therapeutic target in neuroblastic tumors. Clin Cancer Res 11: 380-389, 2005.

11. Matsui T, Sano K, Tsukamoto T, Ito M, Takaishi T, Nakata H, Nakamura $\mathrm{H}$ and Chihara K: Human neuroblastoma cells express alpha and beta platelet-derived growth factor receptors coupling with neurotrophic and chemotactic signalling. J Clin Invest 92: 1153-1160, 1993.

12. Uren A, Merchant MS, Sun CJ, Vitolo MI, Sun Y, Tsokos M, Illei PB, Ladanyi M, Passaniti A, Mackall C and Toretsky JA: Beta-platelet-derived growth factor receptor mediates motility and growth of Ewing's sarcoma cells. Oncogene 22: 2334-2342, 2003.

13. Zwerner JP and May WA: PDGF-C is an EWS/FLI induced transforming growth factor in Ewing family tumors. Oncogene 20: 626-633, 2001.

14. Lombardo LJ, Lee FY, Chen P, Norris D, Barrish JC, Behnia K, Castaneda S, Cornelius LA, Das J, Doweyko AM, Fairchild C, Hunt JT, Inigo I, Johnston K, Kamath A, Kan D, Klei H, Marathe P, Pang S, Peterson R, Pitt S, Schieven GL, Schmidt RJ, Tokarski J, Wen ML, Wityak J and Borzilleri RM: Discovery of N-(2-chloro-6-methyl- phenyl)-2-(6-(4-(2hydroxyethyl)-piperazin-1-yl)-2-methylpyrimidin-4ylamino)thiazole-5-carboxamide (BMS-354825), a dual $\mathrm{Src} / \mathrm{Abl}$ kinase inhibitor with potent antitumor activity in preclinical assays. J Med Chem 47: 6658-6661, 2004.

15. Chen Z, Lee FY, Bhalla KN and Wu J: Potent inhibition of platelet-derived growth factor-induced responses in vascular smooth muscle cells by BMS-354825 (dasatinib). Mol Pharmacol 69: 1527-1533, 2006.

16. Schittenhelm MM, Shiraga S, Schroeder A, Corbin AS, Griffith D, Lee FY, Bokemeyer C, Deininger MW, Druker BJ and Heinrich MC: Dasatinib (BMS-354825), a dual SRC/ABL kinase inhibitor, inhibits the kinase activity of wild-type, juxtamembrane, and activation loop mutant KIT isoforms associated with human malignancies. Cancer Res 66: 473-481, 2006.

17. Thiele CJ, McKeon C, Triche TJ, Ross RA, Reynolds CP and Israel MA: Differential protooncogene expression characterizes histopathologically indistinguishable tumors of the peripheral nervous system. J Clin Invest 80: 804-811, 1987.

18. Johnson FM, Saigal B, Talpaz M and Donato NJ: Dasatinib (BMS-354825) tyrosine kinase inhibitor suppresses invasion and induces cell cycle arrest and apoptosis of head and neck squamous cell carcinoma and non-small cell lung cancer cells. Clin Cancer Res 11: 6924-6932, 2005.

19. Motohashi T, Aoki H, Chiba K, Yoshimura N and Kunisada T: Multipotent cell fate of neural crest-like cells derived from embryonic stem cells. Stem Cells 25: 402-410, 2007.

20. Scotlandi K, Manara MC, Strammiello R, Landuzzi L, Benini S, Perdichizzi S, Serra M, Astolfi A, Nicoletti G, Lollini PL, Bertoni F, Nanni P and Picci P: C-kit receptor expression in Ewing's sarcoma: lack of prognostic value but therapeutic targeting opportunities in appropriate conditions. J Clin Oncol 21: 1952-1960, 2003.

21. Nam S, Kim D, Cheng JQ, Zhang S, Lee JH, Buettner R, Mirosevich J, Lee FY and Jove R: Action of the Src family kinase inhibitor, dasatinib (BMS-354825), on human prostate cancer cells. Cancer Res 65: 9185-9189, 2005.

22. Shor AC, Keschman EA, Lee FY, Muro-Cacho C, Letson GD, Trent JC, Pledger WJ and Jove R: Dasatinib inhibits migration and invasion in diverse human sarcoma cell lines and induces apoptosis in bone sarcoma cells dependent on Src kinase for survival. Cancer Res (In press).

23. Trevino JG, Summy JM, Lesslie DP, Parikh NU, Hong DS, Lee FY, Donato NJ, Abbruzzese JL, Baker CH and Gallick GE: Inhibition of SRC expression and activity inhibits tumor progression and metastasis of human pancreatic adenocarcinoma cells in an orthotopic nude mouse model. Am J Pathol 168: 962-972, 2006.

24. DeMali KA, Godwin SL, Soltoff SP and Kazlauskas A: Multiple roles for Src in a PDGF-stimulated cell. Exp Cell Res 253: 271-279, 1999. 
25. Kushner BH and Meyers PA: How effective is doseintensive/myeloablative therapy against Ewing's sarcoma/ primitive neuroectodermal tumor metastatic to bone or bone marrow? The Memorial Sloan-Kettering experience and a literature review. J Clin Oncol 19: 870-880, 2001.

26. Beppu K, Jaboine J, Merchant MS, Mackall CL and Thiele CJ: Effect of imatinib mesylate on neuroblastoma tumorigenesis and vascular endothelial growth factor expression. J Natl Cancer Inst 96: 46-55, 2004.

27. Merchant MS, Woo CW, Mackall CL and Thiele CJ: Potential use of imatinib in Ewing's Sarcoma: evidence for in vitro and in vivo activity. J Natl Cancer Inst 94: 1673-1679, 2002.

28. Te KG, Timeus F, Rinaldi A, Crescenzio N, Spinelli M, Rosolen A, Ricotti E and Basso G: Imatinib mesylate (STI571) interference with growth of neuroectodermal tumour cell lines does not critically involve c-Kit inhibition. Int J Mol Med 14: 373-382, 2004.
29. Bond M, Bernstein ML, Pappo A, Schultz KR, Krailo M, Blaney SM and Adamson PC: A phase II study of imatinib mesylate in children with refractory or relapsed solid tumors: A Children's Oncology Group study. Pediatr Blood Cancer (In press).

30. Zwaan CM, den Boer ML, Beverloo B, van der Velden V, Countouriotis A, Strauss L, Astier L, Apanovitch A, Landman-Parker J and Kearns P: Dasatinib (SPRYCEL) in children and adolescents with relapsed or refractory leukemia: preliminary results of the CA180018 phase I/II study. Blood 108: Abs. 2162, 2006. 